\title{
BACTERIAL FERRIHYDRITE NANOPARTICLES: PREPARATION, MAGNETIC PROPERTIES, AND APPLICATION IN MEDICINE
}

\author{
S. V. Stolyar ${ }^{1,2,3}$, D. A. Balaev ${ }^{1,2}$, V. P. Ladygina ${ }^{3}$, A. A. Dubrovskiy ${ }^{2}$, A. A. Krasikov ${ }^{2}$, \\ S. I. Popkov ${ }^{1,2}$, O. A. Bayukov², R. N. Yaroslavtsev ${ }^{1,2}$, M. N. Volochaev ${ }^{2}$, \\ R. S. Iskhakov ${ }^{2}$, K. G. Dobretsov ${ }^{4}$, E. V. Morozov ${ }^{2,3}$, O. V. Falaleev ${ }^{2,3}$, \\ E. V. Inzhevatkin ${ }^{3}$, O. A. Kolenchukova ${ }^{5}$, and I. A. Chizhova ${ }^{1}$ \\ ${ }^{1}$ Siberian Federal University, Krasnoyarsk, 660041 Russia \\ ${ }^{2}$ Kirensky Institute of Physics, Federal Research Center KSC SB RAS, Krasnoyarsk, 660036 \\ Russia \\ ${ }^{3}$ Krasnoyarsk Scientific Center, Federal Research Center KSC SB RAS, Krasnoyarsk, 660036 \\ Russia \\ ${ }^{4}$ Siberian Clinical Center FMBA, Krasnoyarsk, Russa \\ ${ }^{5}$ Scientific Research Institute of Medical Problems of the North, Federal Research Center KSC \\ SB RAS, Krasnoyarsk, 660022 Russia \\ e-mail: stol@iph.krasn.ru
}

\begin{abstract}
Nanoparticles of antiferromagnetically ordered materials acquire the uncompensated magnetic moment caused by defects and surface effects. A bright example of such a nanoantiferromagnet is nanoferrihydrite consisting of particles $2-5 \mathrm{~nm}$ in size, the magnetic moment of which amounts to hundreds of Bohr magnetons per particle. We present a brief review of the studies on magnetic properties of ferrihydrite produced by bacteria. Special attention is focused on the aspects of possible biomedical applications of this material, i.e., the particle elimination, toxicity, and possible use for targeted drug delivery.
\end{abstract}

\section{Introduction}

The materials containing magnetic nanoparticles are interesting both for fundamental research concerning the drastic difference of their magnetic properties from those of bulk analogs and for application in various fields $[1,2]$. It is well-known that as the size of ferro- and ferrimagnetic particles decreases, surface atoms start playing a decisive role in the magnetic state formation. This often leads to a decrease in the saturation magnetization of a nanostructured material due to the break of chemical bonds and spin-glass state of surface atoms [3]. As a result, magnetic moment $\mu_{\mathrm{P}}$ of ferro- and ferrimagnetic nanoparticles decreases with particle size $d$ much faster than the quantity proportional to particle volume $V\left(V \sim d^{3}\right)[3-5]$.

In the antiferromagnetically (AFM) ordered nanoparticles, the surface effects and defects in the bulk of particles play a fundamentally different role: these particles acquire uncompensated magnetic moment $\mu_{\mathrm{unc}},\left(\mu_{\mathrm{P}}=\mu_{\mathrm{unc}}\right)$, the value of which depends on the particle size and defect type. Based on the statistical considerations, Neel proposed the interrelation between number of atoms $\mathrm{N}$ in a particle (obviously, $\mathrm{N} \sim \mathrm{V}$ ), uncompensated magnetic moment $\mu_{\text {unc }}$, and defect type [6]

$$
\mu_{\mathrm{unc}} \sim \mu_{\mathrm{at}} \mathrm{N}^{b} .
$$

Here, $\mu_{\text {at }}$ is the magnetic moment of a magnetically active atom and $b$ is the exponent that takes the values of $1 / 3,1 / 2$, or $2 / 3$ for defects on the surface and in the bulk of a particle or the odd number of ferromagnetically ordered planes in a particle. Indeed, according to the data reported in [2, 7-15], equality (1) is valid for AFM nanoparticles of different compositions. This gives grounds for studying the fundamental properties of AFM nanoparticles and opens the opportunities for their application, e.g., in medicine, due to the fact that an AFM particle of a few 
nanometers in size can have a magnetic moment comparable with that of a ferro- or ferrimagnetic particle.

Ferrihydrite with the nominal chemical formula $5 \mathrm{Fe}_{2} \mathrm{O}_{3} \cdot 9 \mathrm{H}_{2} \mathrm{O}$ (the number of $\mathrm{OH}$ bonds and water content can change under the action of structural defects) stands out from the diversity of AFM-ordered nanoparticle types. This mineral exists in the nanosized form in almost all living organisms and works as an iron repository, being a part of the so-called ferritin. Ferritin extracted from a horse spleen was thoroughly investigated [7, 10, 14, 15]. It was established that the $\mu_{\mathrm{unc}}$ value for ferritin with a ferrihydrite core $\sim 5 \mathrm{~nm}$ in size amounts to several Bohr magnetons $\left(\mu_{\mathrm{B}}\right)$.

Ferrihydrite nanoparticles can be obtained using chemical methods [16, 17] or by extracting the products of bacteria vital activity. One of the techniques for preparing bacterial ferrihydrite is based on cultivation of Klebsiella oxytoca bacteria from lake bottom sediments $[18,19]$. This study presents a brief review of the investigations of the magnetic properties of bacterial ferrihydrite nanoparticles, the possibility of targeted particle coarsening by heat treatment $[20,21]$ and, as a consequence, modification of the magnetic properties of this material, and the results of the clinical examination of laboratory animals with the use of ferrihydrite nanoparticles.

\section{Preparation and characterization of biogenic ferrihydrite nanoparticles}

The Klebsiella oxytoca strain used for producing ferrihydrite was extracted from the sapropel of the Borovoe lake, Krasnoyarsk territory. Microorganisms were inoculated into an agar medium and grown under anaerobic conditions. After multiple ultrasonic processing of bacterial sediments, centrifugation, and washing, a stable sol of nanoparticles in an aqueous solution was fabricated and dried. The obtained powder of magnetic nanoparticles is hereinafter referred to as as-prepared sample. Note that as-prepared samples of different sets demonstrated similar characteristics. A part of the powder was kept in air at temperatures within the range of $150^{-} 200^{\circ} \mathrm{C}$ for different times.

$\mathrm{X}$-ray diffraction patterns of the prepared samples are characteristic of the amorphous state. The ferrihydrite nanoparticles were characterized by Mössbauer spectroscopy. According to the Mössbauer spectra, iron atoms in bacterial ferrihydrite can occupy three sites with different quadrupole splittings characteristic of ferrihydrite [18, 20, 22]. The results of analysis of Mössbauer spectra are mainly identical for as-prepared samples of different sets. The formation of new iron oxide phases in bacterial ferrihydrite upon annealing was not observed $[13,20]$.

Typical transmission electron microscopy (TEM) data for the as-prepared ferrihydrite sample are shown in the Fig.1. The average ferrihydrite nanoparticle size $<\mathrm{d}>$ estimated from several micrographs was found to be $\sim 2.7 \mathrm{~nm}$. The low-temperature heat treatment leads to the increase in the particle size (the $\langle\mathrm{d}\rangle$ value of the sample treated at $150^{\circ} \mathrm{C}$ for $24 \mathrm{~h}$ is $\sim 4 \mathrm{~nm}$ ). 

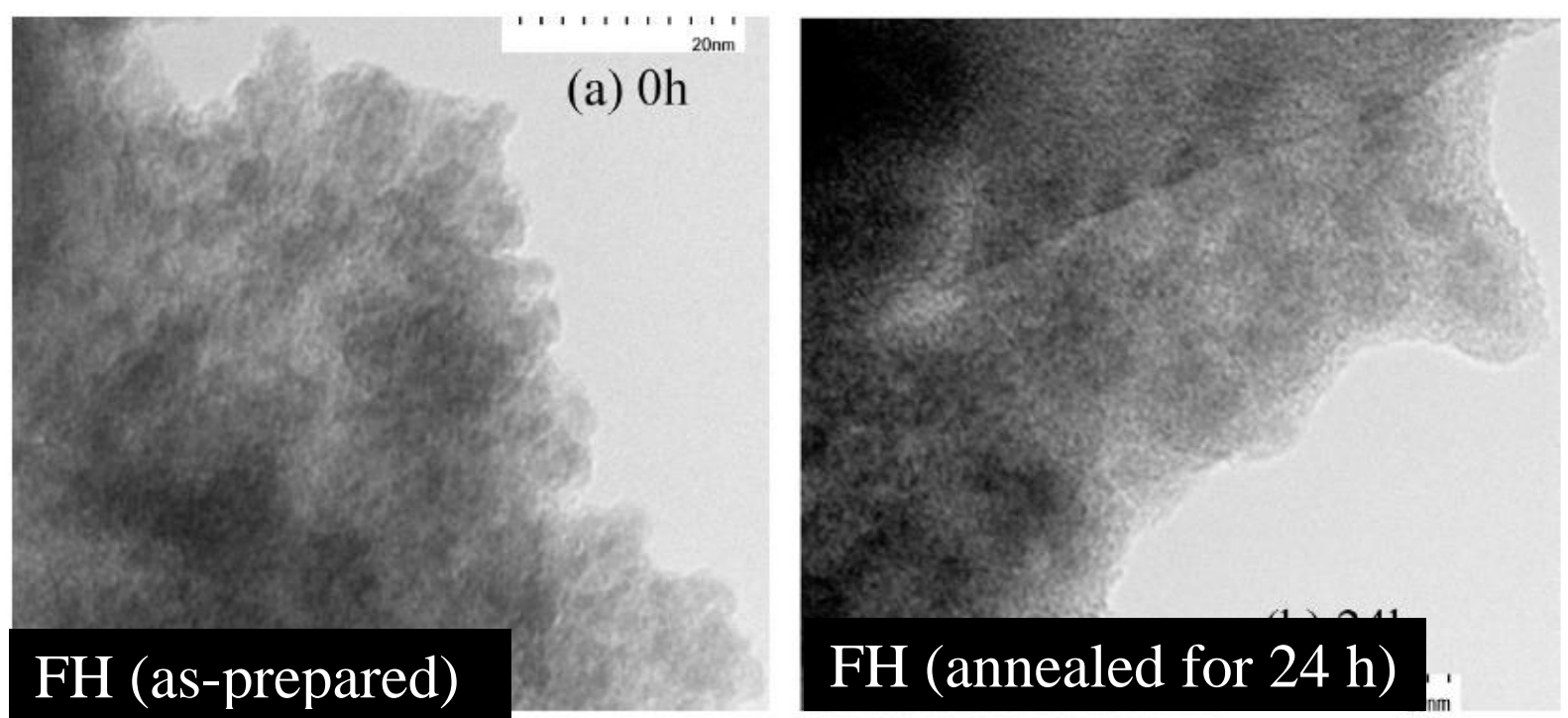

Fig.1. Typical TEM micrographs obtained using a Hitachi HT7700 facility.

\section{Magnetic properties of bacterial ferrihydrite nanoparticles and their transformation upon low-temperature heat treatment}

3.1. Superparamagnetic behavior of bacterial ferrihydrite nanaoparticles, the origin of uncompensated magnetic moment and the effect of low temperature heat annealing.

Figure 2 presents typical temperature dependences of the magnetic moment $\mathrm{M}(\mathrm{T})$ obtained upon cooling the ferrihydrite samples annealed for different times at temperatures of 150 and $200^{\circ} \mathrm{C}$ in the nonzero (FC) and nonzero (ZFC) external field modes. The difference between the $\mathrm{M}(\mathrm{T})_{\mathrm{ZFC}}$ and $\mathrm{M}(\mathrm{T})_{\mathrm{FC}}$ dependences and the pronounced maximum in the $\mathrm{M}(\mathrm{T})_{\mathrm{ZFC}}$ dependences evidence for the superparamagnetic (SP) behavior of the investigated particles. In addition, according to our data, the maximum temperature (hereinafter, blocking temperature $T_{B}$ ) shifts toward lower temperatures, which is typical of the SP systems. Note that for the as-prepared ferrihydrite samples from different series the $T_{B}$ value in the same field differed by no more than $3 \mathrm{deg}$ and lied between $23-25 \mathrm{~K}(\mathrm{H}=1 \mathrm{kOe})$. In addition, it can be seen in Fig. 2 that annealing significantly increases the blocking temperature and this effect is governed by the annealing temperature and time.

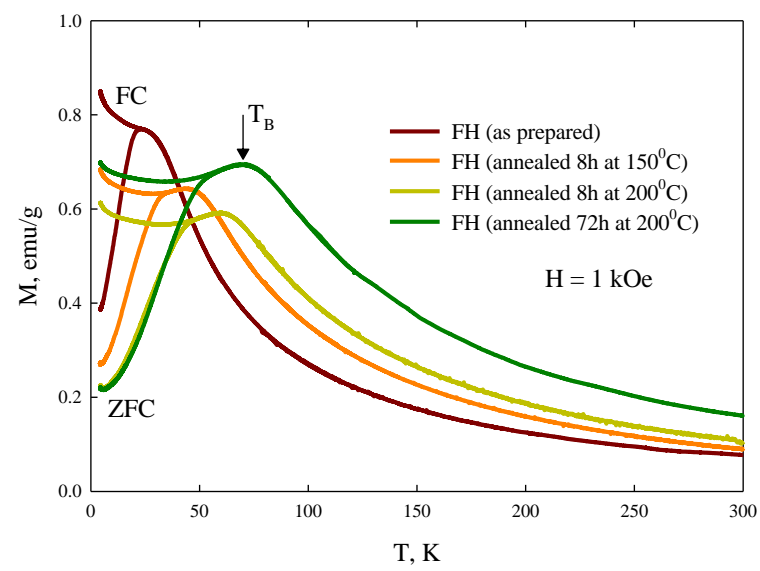

Fig. 2. FC and ZFC M(T) dependences for the as-prepared and annealed ferrihydrite samples. 
Based on the classical Néel-Brown relation

$$
\mathrm{kT}_{\mathrm{B}}=\mathrm{K}_{\mathrm{eff}} \mathrm{V} / \ln \left(\tau / \tau_{0}\right) \approx \mathrm{K}_{\mathrm{eff}} \mathrm{V} / 25,
$$

where $\mathrm{k}$ is the Boltzmann constant, $\mathrm{K}_{\mathrm{eff}}$ is the effective magnetic anisotropy constant; $\mathrm{V}$ is the particle volume; $\tau$ and $\tau_{0} \sim 10^{-9}-10^{-10} \mathrm{~s}$ are the characteristic times of the measurements ( $\tau \sim 10^{2} \mathrm{~s}$ for the magnetic measurements) and particle relaxation, we may conclude that the annealing increases the particle size. This is confirmed by the TEM data (Fig. 1).

The particle size growth during annealing is confirmed also by the magnetization curves $\mathrm{M}(\mathrm{H})$ in the temperature range of $\mathrm{T}>\mathrm{T}_{\mathrm{B}}$. Figure 3 shows magnetization isotherms for the asprepared samples and the samples annealed at $160^{\circ} \mathrm{C}$ for $24 \mathrm{~h}$. According to the generally accepted approach, the magnetization curve of the ensemble of AFM nanoparticles in the region of $\mathrm{T}>\mathrm{T}_{\mathrm{B}}$ can be described by the expression

$$
\mathrm{M}(\mathrm{H})=\mathrm{N}_{\mathrm{P}} \int_{0}^{\infty} L\left(\mu_{P}, H\right) f\left(\mu_{P}\right) \mu_{P} d \mu_{P}+\chi_{\mathrm{AF}} \times \mathrm{H} .
$$
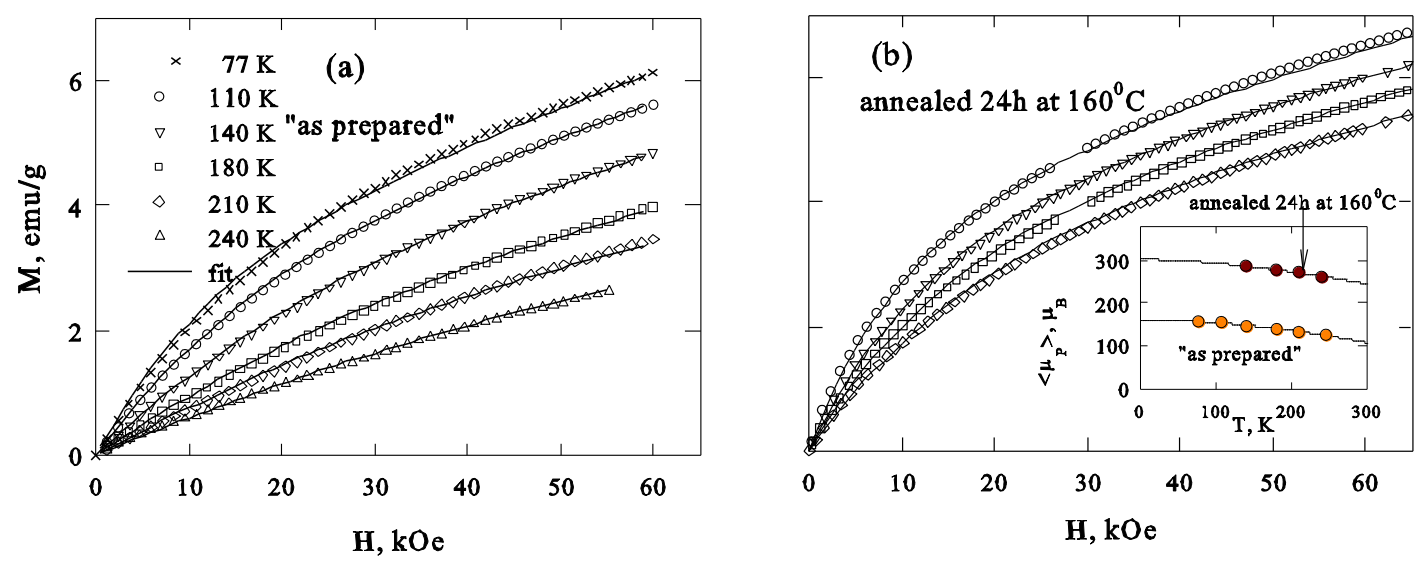

Fig. 3. Experimental (dots) and fitting (lines, expression (3)) $\mathrm{M}(\mathrm{H})$ dependences for the ferrihydrite samples. The inset on the left shows the temperature behavior of fitting parameter $\left\langle\mu_{\mathrm{P}}\right\rangle$.

This expression was written with regard to the distribution over magnetic moments $f\left(\mu_{\mathrm{P}}\right)$. The first term of (3) describes the alignment of particle magnetic moments $\mu_{\mathrm{P}}$ along the external field direction in accordance with the classical Langevin function $L\left(\mu_{P}, H\right)$ $\left(\mathrm{L}\left(\mu_{\mathrm{P}}, \mathrm{H}\right)=\operatorname{coth}\left(\mu_{\mathrm{P}} \times \mathrm{H} / \mathrm{kT}\right)-1 /\left(\mu_{\mathrm{P}} \times \mathrm{H} / \mathrm{kT}\right) ; \mathrm{N}_{\mathrm{P}}\right.$ is the number of particles in unit mass. The second term $\chi_{\mathrm{AF}} \times \mathrm{H}$ describes the cant of sublattices of the AFM particle core $\left(\chi_{\mathrm{AF}}\right.$ is the AFM susceptibility of the particle core). Solid lines in Fig. 3 show the best fitting of the experimental data by expression (3) using the lognormal distribution over the magnetic moments: $f\left(\mu_{\mathrm{P}}\right)=\left(\mu_{\mathrm{P}} \cdot \mathrm{s} \cdot(2 \pi)^{1 / 2}\right)^{-1} \exp \left\{-\left[\ln \left(\mu_{\mathrm{P}} / \mathrm{n}\right)\right]^{2} / 2 \mathrm{~s}^{2}\right\}$, where $\left\langle\mu_{\mathrm{P}}\right\rangle=\mathrm{n} \cdot \exp \left(\mathrm{s}^{2}\right)$ is the average particle magnetic moment and $\mathrm{s}^{2}$ is the $\ln \left(\mu_{\mathrm{P}}\right)$ dispersion.

The inset in Fig. 3b illustrates the temperature behavior of $\left\langle\mu_{\mathrm{P}}\right\rangle$, which is described well by the law $\left\langle\mu_{\mathrm{P}}(\mathrm{T})\right\rangle=\left\langle\mu_{\mathrm{P}}(\mathrm{T}=0)\right\rangle \times\left(1-\mathrm{T}^{a}\right)$ at typical $a$ values between 1.5-2.0. It can be seen that annealing leads to a noticeable increase in $\left\langle\mu_{\mathrm{P}}\right\rangle$. This allows us to reliably determine the $\left\langle\mu_{\mathrm{P}}\right\rangle$ value from the $\mathrm{M}(\mathrm{H})$ data at $\mathrm{T}=0$ for the as-prepared and annealed samples $\left(162 \mu_{\mathrm{B}}\right.$ and $302 \mu_{\mathrm{B}}$, respectively). These values correspond to the numbers of uncompensated iron atoms of $\sim 30$ and 
$\sim 60$ (at $\left.\mu_{\mathrm{Fe} 3+}=5 \mu_{\mathrm{B}}\right)$ and agree well with the model Neel hypothesis with the exponent $b \approx 1 / 2$ in Eq. (1). Indeed, using the values of $\langle\mathrm{d}\rangle \approx 2.7 \mathrm{~nm}$ for the as-prepared sample and $\sim 4.0 \mathrm{~nm}$ for the annealed sample (Fig. 1 shows the data for this sample series) and taking an average distance of $0.31 \mathrm{~nm}$ between $\mathrm{Fe}$ atoms in ferrihydrite [9], we obtain the numbers of iron atoms of $\mathrm{N} \sim 600$ and 2200 in the approximation of the cubic particle shape and, consequently, $\mathrm{N}^{1 / 2} \approx 25$ and $\approx 47$. Thus, the uncompensated magnetic moment of the bacterial ferrihydrite occurs due to defects both on the surface and in the bulk of a sample.

The dependence of the quantity $\left\langle\mu_{\mathrm{P}}(\mathrm{T}=0)\right\rangle$ on annealing time is illustrated in Fig. 4. It seems reasonable to explain the particle coarsening upon annealing by the agglomeration of neighboring particles $[20,21]$ : note that at higher temperatures, ferrihydrite decomposes with the formation of the hematite phase [22]. One may conclude that low-temperature annealing on air is the effective way to change the size as well as magnetic properties (the blocking temperature, the value of uncompensated magnetic moment) of ferrihydrite nanoparticles.

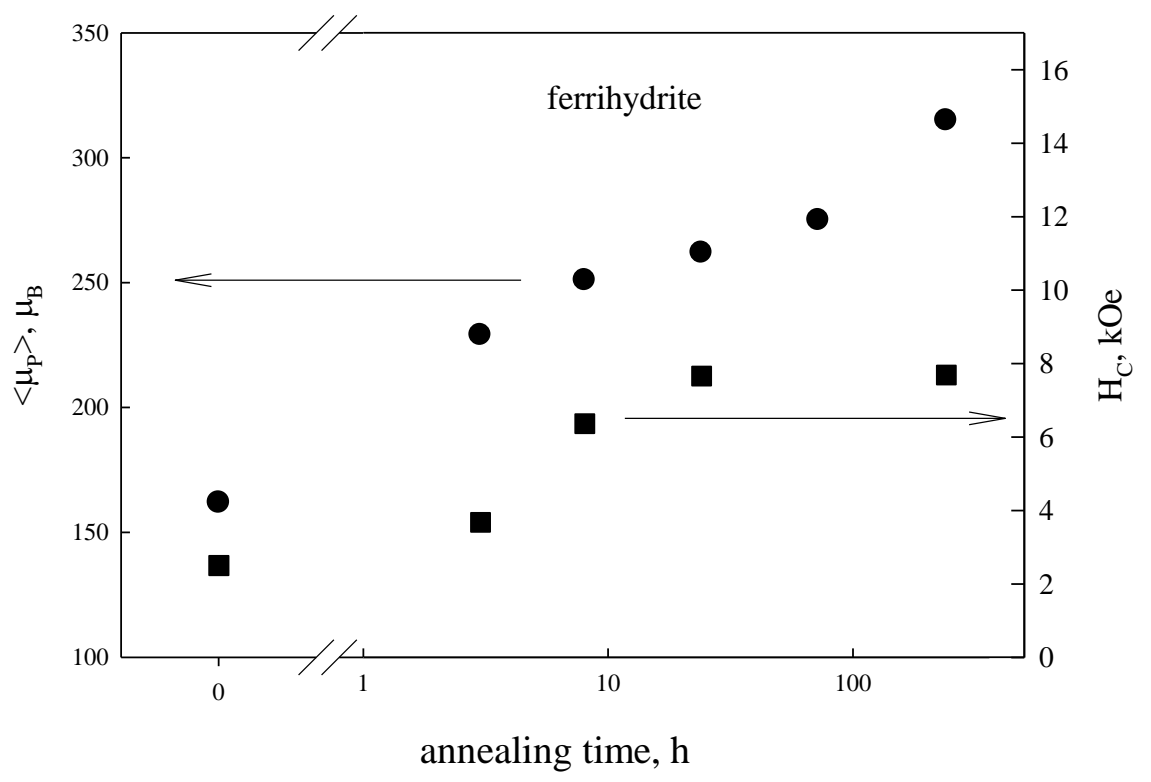

Fig. 4. Average magnetic moment $\left\langle\mu_{\mathrm{P}}(\mathrm{T}=0)\right\rangle$ of ferrihydrite particles (left scale) and coercivity $\mathrm{H}_{\mathrm{C}}$ (at $\mathrm{T}=4.2 \mathrm{~K}$ and $\mathrm{H}_{\max }=60 \mathrm{kOe}$, ) vs time of annealing at $160^{\circ} \mathrm{C}$.

3.2.

Within the temperature range $\mathrm{T}<\mathrm{T}_{\mathrm{B}}$ the isotherms of magnetization $\mathrm{M}(\mathrm{H})$ are hysteretic. At $\mathrm{T}=4.2 \mathrm{~K}$ the value of coercivity $\mathrm{H}_{\mathrm{C}}$ (obtained from $\mathrm{M}(\mathrm{H})$ curves measured at the maximal applied field $\mathrm{H}_{\max }= \pm 60 \mathrm{kOe}$ ) lies within 1.5-3.0 kOe for as prepared samples from different series. Low-temperature annealing leads (besides increase in size, $T_{B}$ and $\left\langle\mu_{P}\right\rangle$ values, see Sec.3.1) to enhancement of coercivity at $\mathrm{T}=4.2 \mathrm{~K}$. The Fig. 4 shows this behavior. This is in accordance with Stoner-Wohlfarth expression for single domain particles: $\mathrm{H}_{\mathrm{C}} \approx \frac{\mathrm{K}_{\text {eff }}}{\mathrm{M}_{\mathrm{S}}}[1-$ $\left.\left(T / T_{B}\right)^{1 / 2}\right]$, where $M_{S}-$ is the saturation magnetization. Indeed, $M_{S}=\mu_{P} / V$ and $\mu_{P} \sim N^{1 / 2} \sim V^{1 / 2}$. Therefore, $\mathrm{M}_{\mathrm{S}} \sim \mathrm{V}^{-1 / 2}$ and $\mathrm{H}_{\mathrm{C}} \sim \mathrm{V}^{1 / 2}$, i.e., coercivity increases with growth of particle size.

From the other hand, AF nanoparticles are known to exhibit very high irreversibility field []. Therefore, in the most cases the $\mathrm{M}(\mathrm{H})$ hysteretic dependences are partial []. Also, many authors observed a shift of hysteresis loop on systems of AF nanoparticles after cooling in a magnetic field from a temperature which is higher than the blocking temperature [] (FC 
conditions). However, it is questionable does the shift of $\mathrm{M}(\mathrm{H})$ hysteresis is due to internal effect (exchange bias) or this is an analogue of the minor loop effect after field cooling. Here we show a method how it is possible to separate these effects.

An example of $\mathrm{ZFC} \mathrm{M}(\mathrm{H})$ hysteresis curve obtained by cycling external field up its maximal values $\mathrm{H}_{\max }$ with a gradual increase in the $\mathrm{H}_{\max }$ is shown on Fig.5. $\mathrm{M}(\mathrm{H})$ curves measured after field cooling at $\mathrm{H}=30 \mathrm{kOe}$ are also shown in this figure. The Fig. 6 shows the $\mathrm{H}_{\mathrm{C}}$ values as a function of maximal applied field $\mathrm{H}_{\text {max }}$ deduced from $\mathrm{M}(\mathrm{H})$ data (Fig.5) for both $\mathrm{ZFC}$ and $\mathrm{FC}$ cases. It is seen that $\mathrm{H}_{\mathrm{C}}\left(\mathrm{H}_{\max }\right)$ dependence has a tendency to saturation. Silva [silva] argued that this dependence can be described by the following expression:

$$
\mathrm{H}_{\mathrm{C}}\left(\mathrm{H}_{\max }\right)=\mathrm{H}_{\text {Cinf }}\left[1-\left(\mathrm{H}^{*} / \mathrm{H}_{\max }\right)^{\beta}\right] .
$$

Here $\mathrm{H}_{\text {Cinf }}$ - is the "infinite coercivity" (i.e. $\mathrm{H}_{\mathrm{C}}$ at high $\mathrm{H}_{\max }$ ). Expression (3) is valid at the fields higher than $\mathrm{H}^{*}$, and the exponent $\beta$ is determined by the structure of energy barriers which the particle moment $\mu_{\mathrm{P}}$ overcomes during magnetization process [silva]. Experimental data $\mathrm{H}_{\mathrm{C}}\left(\mathrm{H}_{\max }\right)$ are well described by expression (4) within the range $\mathrm{H}>30 \mathrm{kOe}$ at $\beta=\& \&, \mathrm{H}^{*}=\& \&$, and $\mathrm{H}_{\text {Cinf }} \approx 3.8 \mathrm{kOe}$. The magnitude of $\mathrm{H}_{\text {Cinf }}$ is shown on Fig. 6 as horizontal dashed line. It is seen

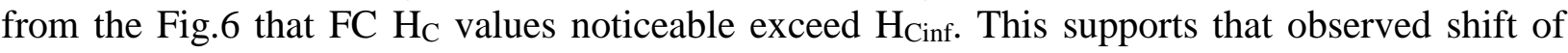
$\mathrm{M}(\mathrm{H})$ loop after field cooling is due to internal effect.

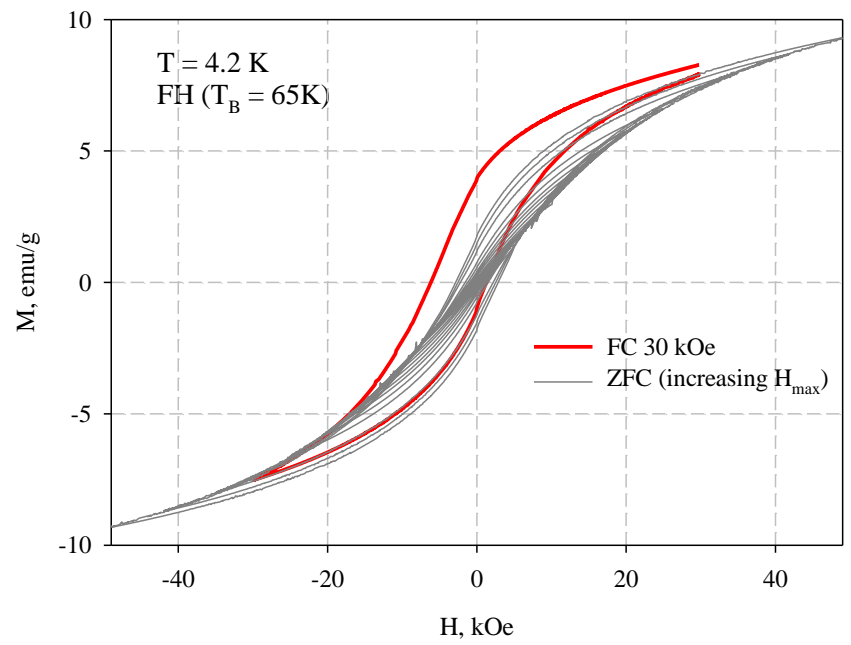

There are at least two possible mechanisms of this behavior. The first mechanism is exchange bias which is known to take place in FM/AF (FM - is ferro- or ferrimagnet) structures (films) or core/shell nanoparticles []. In the case of "pure" AF nanoparticles there is a possibility of exchange coupling between uncompensated magnetic moment $\mu_{P}(\mathrm{FM})$ and AF "core" of a particle []. The second mechanism was pointed out by Berkowits and Kodama; they have shown that existence of large number of the broken exchange bonds on the surface can lead to the occurrence of the multi-sublattice states in an AF nanoparticle and this may result to the shift of $\mathrm{M}(\mathrm{H})$ loop after field cooling. The Fig.7 shows the dependence $\mathrm{H}_{\mathrm{EB}}$ as a function of particle size $\mathrm{d}$ obtained on ferrihydrite samples undergone heat treatment for different times. The loop shift is not observed for ferrihydrite nanoparticles whose size is less than $3 \mathrm{~nm}$. Increase of $\mathrm{H}_{\mathrm{EB}}$ values with size is seen from the Fig.7. Similar behavior was observed on $\mathrm{CuO}$ and $\mathrm{NiO}$ nanoparticles..... 


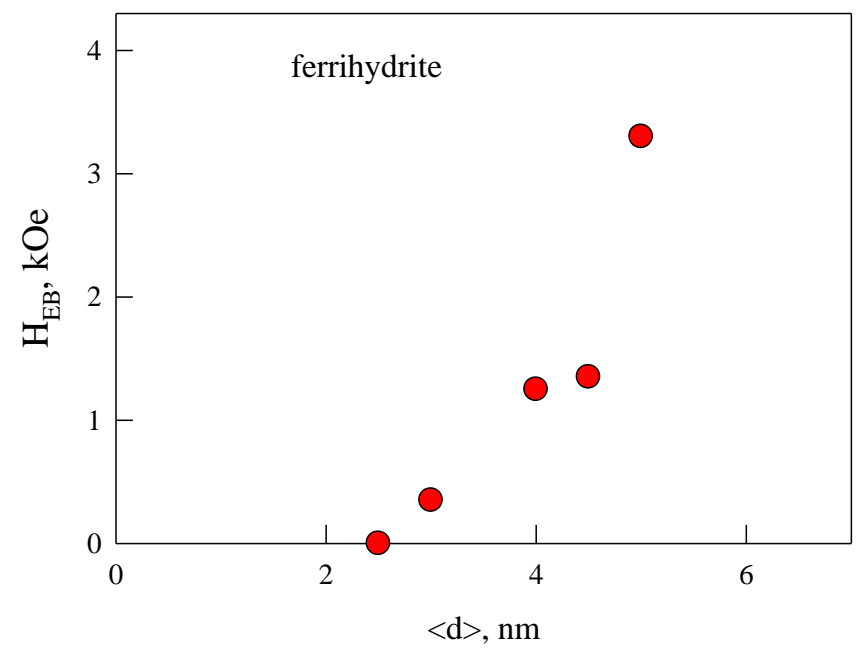

We emphasis that

So, observed shift of $\mathrm{M}(\mathrm{H})$

In this expression, suggested in Ref.[Silva], Here $\mathrm{H}_{\text {Cinf }}$ - is the coercivity at "infinite" external field, and $\mathrm{H}^{*}$ determines the range where this dependence explain e.

up to varito different maximum magnetic fields

model which predicts $\Phi A$

A typical example of

\section{Possible applications in medicine}

\subsection{Elimination of ferrihydrite nanoparticles from the organism}

Elimination of ferrihydrite nanoparticles from the organism was studied by NMR tomography on laboratory animals (mice). The suspension containing $0.7 \mathrm{~g} / \mathrm{l} \mathrm{H}_{2} \mathrm{O}$ was injected singly abdominally in amount of $1 \mathrm{ml}$ or singly intramuscularly in a thigh in amount of $0.1 \mathrm{ml}$.

The tomography study was carried out on a Bruker Avance DPX 200 NMR facility in a field of $4.7 \mathrm{~T}$ with a Greate $3 / 60$ gradient block. The ${ }^{1} \mathrm{H}$ nuclear tomographic images were obtained by a spin-echo technique [23].

Figure 5 shows typical tomographic images of the thigh cross section in 15 min and $2 \mathrm{~h}$ after the intramuscular injection of the suspension. For a time period of $15 \mathrm{~min}$, the signal intensity noticeably increases (shown by the arrow in Fig. 5a), which is reasonable to attribute to the presence of magnetic nanoparticles. However, for a period of $2 \mathrm{~h}$, we noticed no changes in the signal intensity within the sensitivity of the method (10 $\mu \mathrm{g}$ per $1 \mathrm{~g}$ of tissue). These results were obtained also for the cross-sectional peritoneal cavity images after the abdominal drug injection. Based on the results obtained, we may conclude that ferrihydrite nanoparticles can be eliminated, at least, at the intramuscular and abdominal injection. 

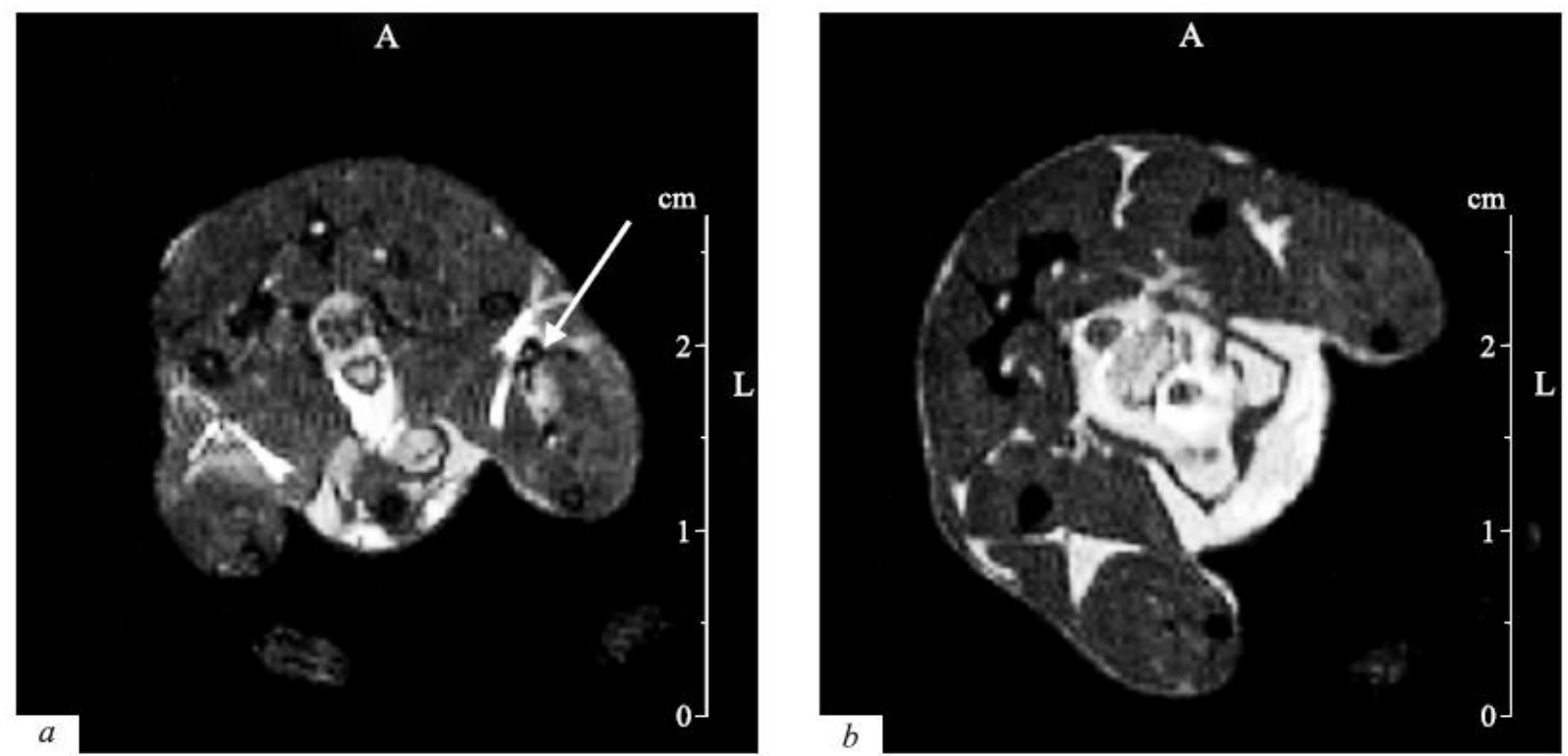

Fig. 5. Tomography images of the thigh cross section in $15 \mathrm{~min}$ and $2 \mathrm{~h}$ after the intramuscular injection of the suspension of ferrihydrite nanoparticles.

\subsection{Targeted drug delivery and nontoxicity of ferrihydrite NPs}

To establish the possibility of targeted drug delivery and effect of magnetic nanoparticles on the conditions of inflammatory and reparative processes of laboratory animals, we compared the results of treatment of three groups of animals (rats). The animals of group I were not treated, the animals of group II were treated by ampicillin, and the animals of group III were treated by ampicillin $(500 \mathrm{mg})$ combined with ferrihydrite nanoparticles. The thermal injury region was affected by an external magnetic field (Polyus-101, magnetic field gradient of 4-6 mT/mm, and magnetic induction of $10-20 \mathrm{mT}$ ) for $20 \mathrm{~min}$.

Macroscopic control of the reparative process of burnt rats showed that in the group of animals treated locally by ampicillin with nanoparticles, the wound healing occurred twofold faster than in the group of animals treated by pure ampicillin (Fig. 6).

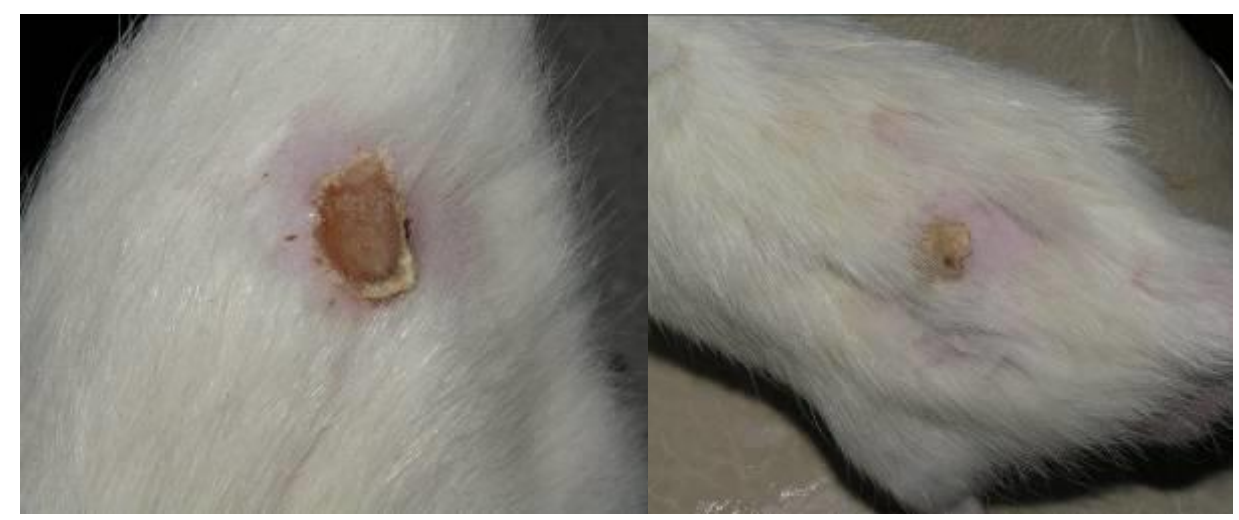

Fig 6. Thermal injury of rats treated by (a) ampicillin and (b) ampicillin with magnetic nanoparticles in seven days.

The cytological examination of thermal injury smears showed that during the first day after the burn all animals experienced the degenerative inflammatory changes. The local use of ampicillin with nanoparticles in group III significantly reduced the inflammation and activated the tissue regeneration, which was reflected in the regenerative inflammatory cytogram type. 
Comparative analysis of the microflora of the rats treated by ampicillin showed that the Staphylococcus bacteria on the thermal injury surface retained their content [25]. The situation was opposite in the group of rats treated by ampicillin with magnetic nanoparticles. The amount of Staphylococcus bacteria was much smaller.

\section{Conclusions}

The nanoparticles of biogenic ferrihydrite obtained from the Klebsiella oxytoca bacteria vital products have the uncompensated magnetic moment caused by defects on the surface and in the bulk of the particles. The presence of a magnetic moment of particles leads to the characteristic SP behavior. The described procedure yields nanoparticles $\sim 3 \mathrm{~nm}$ in size with an SP blocking temperature of $\sim 23-25 \mathrm{~K}$, and an average particle magnetic moment of 150-200 $\mu_{\mathrm{B}}$. Heat treatment at $150-200^{\circ} \mathrm{C}$ increases the $\mathrm{T}_{\mathrm{B}}$ and $\left\langle\mu_{\mathrm{P}}\right\rangle$ values due to the particle coarsening via agglomeration. Note that the particles over $3 \mathrm{~nm}$ in size (or with the $\mathrm{T}_{\mathrm{B}}$ value higher than $40 \mathrm{~K}$ ) exhibit the exchange bias effect, i.e., the magnetic hysteresis loop shift after cooling in an external magnetic field starting from the temperature higher than $T_{B}[26]$.

According to the NMR study, elimination of ferrihydrite nanoparticles at the intermuscular and abdominal injection occurs for the time of no longer than $2 \mathrm{~h}$. The positive results of using the drugs in combination with nanoparticles for treating thermal injuries under the action of a gradient magnetic field together with ferrihydrite nontoxicity open wide opportunities for application of these nanoparticles in biomedicine.

The reported study was funded by Russian Foundation for Basic Research, Government of Krasnoyarsk

Territory, Krasnoyarsk Region Science and Technology Support Fund to the research projects № 17-42240138, 17-43-240527.

\section{References}

1. J. Nogués, J. Sort, V. Langlais, V. Skumryev, S. Suriñach, J.S. Muñoz, M.D. Baró, Physics Reports 422, 65 (2005).

2. S. Mørup, D.E. Madsen, C. Fradsen, C.R.H. Bahl, and M.F. Hansen, J. Phys.: Condens. Matter. 19, P. 213202 (2007).

3. R.H. Kodama, A.E. Berkowitz, Phys. Rev. B 59, 6321 (1999).

4. A. Millan, A. Urtizberea, N.J.O. Silva, F. Palacio, V.S. Amaral, E. Snoeck, V. Serin, J. Magn. Magn. Mater. 312, L5 (2007).

5. V.L. Kirillov, D.A. Balaev, S. V. Semenov, K.A. Shaikhutdinov, O.N. Martyanov, Mater. Chem. Phys. 145 (2014) 75-81.

6. L. Néel, C.R. Acad. Sci. Paris 252, 4075 (1961).

7. S.A. Makhlouf, F.T. Parker, A.E. Berkowitz, Phys. Rev. B 55, R14717 (1997).

8. M.S. Seehra, V.S. Babu, A. Manivannan, J.W. Lynn, Phys. Rev. B 61, 3513 (2000).

9. A. Punnoose, T. Phanthavady, M.S. Seehra, N. Shah, and G.P. Huffman, Phys. Rev. B 69, 054425 (2004).

10. C. Gilles, P. Bonville, H. Rakoto, J.M. Broto, K.K.W. Wong, S. Mann, J. Magn. Magn. Mater. 241, 430 (2002).

11. A.A. Lepeshev, I.V. Karpov, A.V. Ushakov, D.A. Balaev, A.A. Krasikov, A.A. Dubrovskiy, D.A. Velikanov, M.I. Petrov, J. Supercond. Nov. Magn. 30, 931 (2017)

12. D.A. Balaev, A.A. Dubrovskii, A.A. Krasikov, S.V. Stolyar, R.S. Iskhakov, V.P. Ladygina, and E.D. Khilazheva, JETP Lett. 98 (3), 139 (2013).

13. D.A. Balaev, A.A. Krasikov, A.A. Dubrovskii, S.V. Semenov, O.A. Bayukov, S.V. Stolyar, R.S. Iskhakov, V.P. Ladygina, and L.A. Ishchenko, J. Exp. Theor. Phys. 119 (3), 479 (2014). 
14. N.J.O. Silva, V.S. Amaral, A. Urtizberea, R. Bustamante, A. Millan, F. Palacio, E. Kampert and U. Zeitler, S. de Brion, O. Iglesias and A. Labarta, Phys. Rev. B 84, 104427 (2011).

15. N.J.O. Silva, V.S. Amaral, and L.D. Carlos, Phys. Rev. B 71, 184408 (2005).

16. F.M. Michel, L. Ehm, S.M. Antao, P.L. Lee, P.J. Chupas, G. Liu, D.R. Strongin, M.A.A. Schoonen, B.L. Phillips, J.B. Parise, Science 316, 1726 (2007).

17. S.V. Stolyar, R.N. Yaroslavtsev, R.S. Iskhakov, O.A. Bayukov, D.A. Balaeva, A.A. Dubrovskii, A.A. Krasikov, V.P. Ladygina, A.M. Vorotynov, and M.N. Volochaev, Physics of the Solid State, 59, 555 (2017).

18. S.V. Stolyar, O.A. Bayukov, Yu.L. Gurevich, V.P. Ladygina, R. S. Iskhakov, and P. P. Pustoshilov, Inorg. Mater. 41 (6), 638 (2007).

19. Yu.L. Raikher, V.I. Stepanov, S.V. Stolyar, V.P. Ladygina, D.A. Balaev, L.A. Ishchenko, and M. Balasoiu, Phys. Solid State 52 (2), 298 (2010).

20. D.A. Balaev, A.A. Krasikov, A.A. Dubrovskiy, S.I. Popkov, S.V. Stolyar, O.A. Bayukov, R.S. Iskhakov, V.P. Ladygina, R.N. Yaroslavtsev, JMMM 410, 71 (2016).

21. D.A. Balaev, A.A. Krasikov, S.V. Stolyar, R.S. Iskhakov, V.P. Ladygina, R.N. Yaroslavtsev, O.A. Bayukov, A.M. Vorotynov, M.N. Volochaev, and A. A. Dubrovskiy, Phys. Solid State 58 (2), 1782 (2016).

22. S.V. Stolyar, O.A. Bayukov, V.P. Ladygina, R.S. Iskhakov, L.A. Ishchenko, V. Yu Yakovchuk, K.G. Dobretsov, A.I. Pozdnyakov, O.E. Piksina, Phys. Solid State 53, 100 (2011).

23. J. W. Bulte and D. L. Kraitchman, NMR Biomed., 17, No. 7, 484-499 (2004).

24. E.V. Inzhevatkin, E.V. Morozov, E.D. Khilazheva, V.P. Ladygina, S.V. Stolyar, and O.V. Falaleev, Bull. Exp. Biol. Med. 158, 807 (2015).

25. K. Dobretsov, S. Stolyar, A. Lopatin, Acta Otorhinolaryngol. Ital. 35, 97-102 (2015).

26. D.A. Balaev, A.A. Krasikov, A.A. Dubrovskiy, S.I. Popkov, S.V. Stolyar, R.S. Iskhakov, V.P. Ladygina, and R.N. Yaroslavtsev, J. Appl. Phys. 120, 183903 (2016). 